\title{
Two-Stage Fuzzy MCDM for Green Supplier Selection in Steel Industry
}

\author{
Chia-Nan Wang, Thi-Ly Nguyen and Thanh-Tuan Dang
}

\author{
Department of Industrial Engineering and Management, National Kaohsiung University of Science and Technology, Kaohsiung, \\ 80778, Taiwan \\ *Corresponding Author: Thi-Ly Nguyen. Email: i108143107@nkust.edu.tw \\ Received: 21 October 2021; Accepted: 08 December 2021
}

\begin{abstract}
Steel is one of the most powerful industries globally, and the associated products have a tremendous impact on nurturing a sustainable society. Considering environmental concerns within this industry's supply chain is highly successful in saving both energy and natural resources and lowering greenhouse gas emissions. In light of this, sustainable suppliers are considered input partners who play a specific role in the chain of business operations of every enterprise, maintaining them to achieve higher levels of customer satisfaction and thus gain more market share. Supplier selection can be characterized as a multi-criteria decision-making (MCDM) problem under a vague and uncertain environment. In this paper, a hybrid model of fuzzy analytic hierarchy process (FAHP) and fuzzy technique for order of preference by similarity to ideal solution (FTOPSIS) is suggested to determine the most potent green supplier of steel manufacturing in Vietnam based on a complete set of five main criteria (price, quality, delivery, service, environment) through literature review and experts' responses. The significance of each criterion is measured by experts' judgments in linguistic terms, which can be expressed in triangular fuzzy numbers using the FAHP model. Then, the FTOPIS model is deployed to rank alternatives. A case study of Vietnam's top 10 steel manufacturers is implemented to exhibit the model's effectiveness. From FAHP findings, "lead time", "warranty", "defect rate", "supply capacity", and "product price" were recognized as the most impactful criteria. As for the ranking of sustainable suppliers, "Hoa Phat Group Joint-stock company", "Hoa Sen Group", and "Pomina Steel Corporation" are the top three optimal suppliers. In dealing with qualitative data and input uncertainties in the supplier evaluation and selection problem, this paper can suggest more possible solutions and provide significant materials in similar outsourcing selection problems and applications of relevant industries.
\end{abstract}

Keywords: Decision-making process; supplier selection; MCDM; fuzzy AHP; fuzzy TOPSIS; steel industry; Vietnam

\section{Introduction}

There is now a growing awareness of the need for a company to work closely with its supply chain partners to optimize its business processes. Supplier selection is one of the most important components of the purchasing

This work is licensed under a Creative Commons Attribution 4.0 International License, which permits unrestricted use, distribution, and reproduction in any medium, provided the original work is properly cited. 
function, which is essential for enhancing competitiveness and increasing customer satisfaction [1]. Therefore, supply chain management is an important strategy for businesses to deliver secure, scalable, and cost-effective products to their customers while remaining competitive paintings [2]. Green supply chain management includes human toxicity and incorporates environmental supply chain management issues. To enhance the sustainability of supply chain operations, environmental, social, and economic issues must be addressed while selecting suppliers [3]. Therefore, the relationship between buyers and suppliers is crucial for companies to maintain strategic success [4]. The sustainability of green supply chain management has recently emerged as an important and important issue for businesses due to its active approach to strengthening public legislation and protecting the environment as well as public awareness of environmental issues such as global warming, air pollution, toxic substance use, climate change and non-renewable energy depletion [5]. Supplier evaluation and selection is a key operational responsibility for implementing sustainable supply chain operations and is an important environmental issue [6]. Green supplier selection is a multi-criteria decision-making process and an important stage for supply chain management because of its long-term effects on the environment [7]. Decision-making is based on supplier estimates using quantitative and qualitative criteria. Selecting a provider may require searching for a new provider or selecting from existing providers. Therefore, enterprises should use the right supplier selection strategy to identify acceptable partners and maintain their competitive advantage through internationalization [8].

AHP and TOPSIS are well-known for their adaptability and capacity to dissect a decision issue in such a way that subjective assessments for unmeasurable factors are included while assessing options. Exact numbers are employed to express a judgment or a score in traditional AHP and TOPSIS techniques, which have been shown to produce inaccurate information and impair the accuracy of judgments in many real-world scenarios. Incorporating fuzzy theory is a practical technique to handle the uncertain assessments given as triangular fuzzy numbers in order to get a more accurate and robust ranking for the alternatives.

The green supplier selection is investigated in this paper using a hybrid fuzzy analytic hierarchy process (FAHP) and fuzzy technique for order of preference by similarity to ideal solution (FTOPSIS) model with a case study on steel manufacturing in Vietnam. Linguistic values represented by triangular fuzzy numbers were used to evaluate the weighting of the criteria and rank the alternatives. Results analysis was performed to evaluate the effect of the criterion weighted estimate on supplier performance and to interpret the managerial implications of the proposed work. One of the innovations of this work was to conduct a green supplier selection assessment in Vietnam using a combination of the FAHP and FTOPSIS models, which have never been reported in the current literature. The creation of an MCDM strategy for selecting green suppliers in the steel manufacturing industry is the main contribution of the study. The study presents important criteria and sub-criteria for green supplier selection after assessing the requirements of companies in supplier selection, which can assist organizations in identifying weak areas to strengthen green suppliers. The proposed technique provides a framework for integrating price, quality, delivery, service, and environmental factors to represent the need for green supplier selection. This reduces the possibility of incorrect supplier selection.

The outline of this paper is laid out accordingly. A review of previous relevant studies is given in part 2. Part 3 provides the fuzzy AHP and fuzzy TOPSIS models. In part 4, a case study of Vietnam is presented. The results and discussions are presented in part 5. Finally, in the last section, the conclusions and future work are highlighted.

\section{Literature Review}

Recently, along with global warming, environmental protection awareness has been increasingly noticed. As a result, research on green supplier selection has gotten a lot of interest from academia and business. A complete set of supplier selection criteria is utilized in many different industries, such as 
agricultural food, automobile production, electronics, and industry 4.0, among others. Researchers have created a variety of tools and methodologies for making multiple criterion decisions in both independent and integrated ways. For the individual techniques, Jiang et al. [9] proposed a grey decision-making trial and evaluation laboratory (DEMATEL) based analytical network process (ANP), called grey DANP, to find the critical criteria in the selection of green automotive manufacturers in Taiwan. Lu et al. [10] provided the framework for a decision of the green supplier selection by using a fuzzy analytical hierarchy process (fuzzy AHP), possibility degree, and a cloud-based model. Arabsheybani et al. [11] applied a fuzzy multi-objective optimization model based on the ratio analysis (fuzzy MOORA) to evaluate the overall performance of suppliers. Almasi et al. [12] used a multiperiod mathematical model for selecting and assigning orders for a sustainable supplier in the Iranian auto industry. Li et al. [13] extended the technique for order performance by similarity to ideal solution (TOPSIS) through cloud model theory incorporating the advantage of stochastic uncertainty control to solve the two-tier green supplier selection issues. As for the integrated model, Banaeian et al. [8] compared three popular supplier selection methods, including TOPSIS, VIšekriterijumskoKOmpromisnoRangiranje (VIKOR), and grey relational analysis (GRA), to complete the assessment and selection of green suppliers in the agri-food industry. To evaluate green supplier selection in the automotive industry in India, Gupta et al. [14] proposed a system based on multi-criteria decision making (MCDM), utilizing an integrated AHP with other three approaches, namely multi-attributive border approximation area comparison (MABAC), weighted aggregated sum-product assessment (WASPAS), and TOPSIS. To better handle this selection problem in multi-components/multi-suppliers in the manufacturing business in Turkey, Kilic et al. [15] presented an intuitionistic fuzzy TOPSIS (IF-TOPSIS) and a modified two-phase fuzzy goal programming model. To tackle the challenge of picking a green supplier for the automobile sector under uncertainty, Ramakrishnan et al. [16] utilized an integrated model that included the cloud model with TOPSIS. While evaluating the performance of alternative green suppliers, there is some randomness in the human cognition process. Çalık [17] applied the integrated AHP and TOPSIS methodology to develop a new team-based decision-making model based on industry 4.0 aspects of finding the best green supplier. Tab. 1 presents a summary of these studies on green supplier selection using the MCDM method.

Table 1: The summary of methodology approach

\begin{tabular}{|c|c|c|}
\hline Studies [reference] & Methodology & Research area \\
\hline Banaeian et al. [8] & TOPSIS, VIKOR, GRA & $\begin{array}{l}\text { Agriculture and food } \\
\text { processing }\end{array}$ \\
\hline Jiang et al. [9] & Grey DANP & Automotive industry \\
\hline Lu et al. [10] & Fuzzy AHP & Biomass industry \\
\hline Arabsheybani et al. [11] & Fuzzy MOORA & Electronic industry \\
\hline Almasi et al. [12] & Mathematical model & Automotive manufacturing \\
\hline Li et al. [13] & Fuzzy TOPSIS & Solar PV energy \\
\hline Gupta et al. [14] & Fuzzy AHP, TOPSIS, MABAC, WASPAS & Automotive industry \\
\hline Kilic et al. [15] & GP, IF-TOPSIS & Manufacturing industry \\
\hline Ramakrishnan et al. [16] & Fuzzy TOPSIS & Automobile industry \\
\hline Çalık [17] & Fuzzy AHP, fuzzy TOPSIS & Industry 4.0 era \\
\hline
\end{tabular}


In Tab. 2, the list of criteria used in previous studies regarding green supplier selection is presented. Some studies only evaluated a few main criteria, while others have switched to a comprehensive set of criteria, leading to more reliable results. This paper deployed a hybrid FAHP and FTOPSIS methodologies with a case study in Vietnam for choosing sustainable suppliers. A sustainable set of criteria was defined and analyzed, including price criteria (product price, logistics cost, quantity discount), quality criteria (supply capacity, defect rate, reputation supplier), delivery criteria (lead time, on time delivery), service criteria (technology support, warranty, responsiveness, and flexibility), and environment criteria (air emissions, wastewater generation, energy consumption, green policies). The list of criteria was identified by a thorough review of previous literature and was further mitigated with the aid of a panel of experts in the steel manufacturing industry in Viet Nam. Experts acknowledged that the set was complete, addressed many parts of the evaluation process, and suggested it be used as the final set.

In this paper, for the first time, a combination of the FAHP and FTOPSIS model for evaluating and selecting green suppliers with a case study in Vietnam is presented. To the best of the author's knowledge, the proposed model is novel with contributions as follows:

- The paper proposes an effective evaluation model for the green supplier selection process. To fulfill the awareness of sustainable development, the proposed model contains a comprehensive set of green criteria.

- The calculation for weighting the criteria is conducted using AHP with triangular fuzzy numbers of experts' judgments which reflect the decision-making process in uncertain conditions. Then, the FTOPSIS model has the capability and accuracy in ranking the alternatives.

- A case study of the steel manufacturing company in Vietnam is used to test the effectiveness of the proposed model.

- The model's results can provide a guideline for the decision-makers or policymakers for the green supplier evaluation and selection process.

\section{Research Methodology}

\subsection{Process of Paper}

The research flow involves two phases, as indicated in Fig. 1. Firstly, the FAHP model is applied to establish the preferred weight of the list of criteria, which is developed based on the expert's consultant and prior literature study. Price (C1), quality (C2), delivery (C3), service (C4), and environment (C5) are the five main factors and 15 criteria examined in this study. Following that, the FTOPSIS model is applied to rank providers based on decision-maker preferences. It's worth mentioning that each criterion's preference weights and alternative ratings are expressed in verbal terms using triangular fuzzy numbers. The model's effectiveness is proven through a case study of Vietnam's 10 leading steel suppliers. 
IASC, 2022, vol.33, no.2

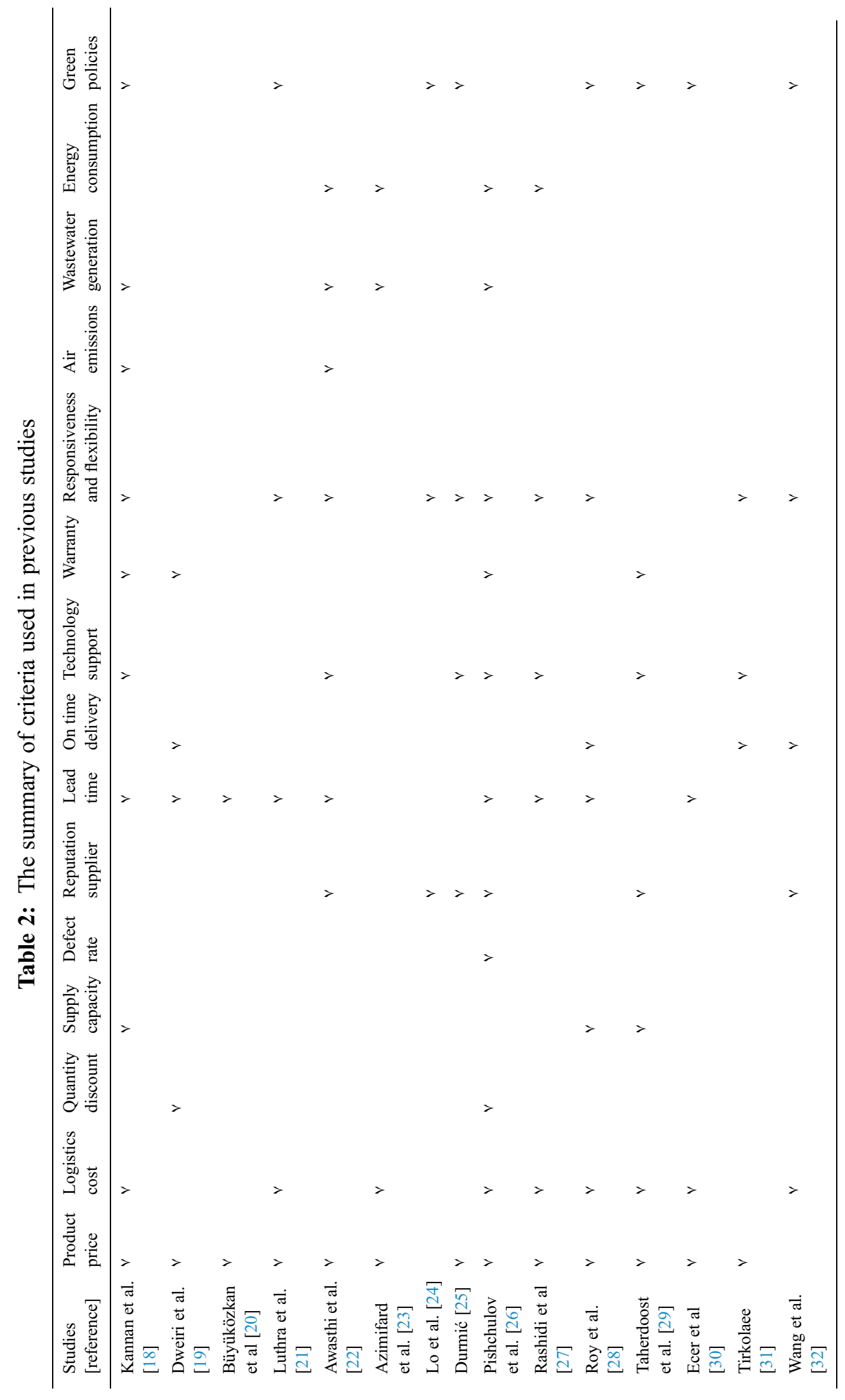




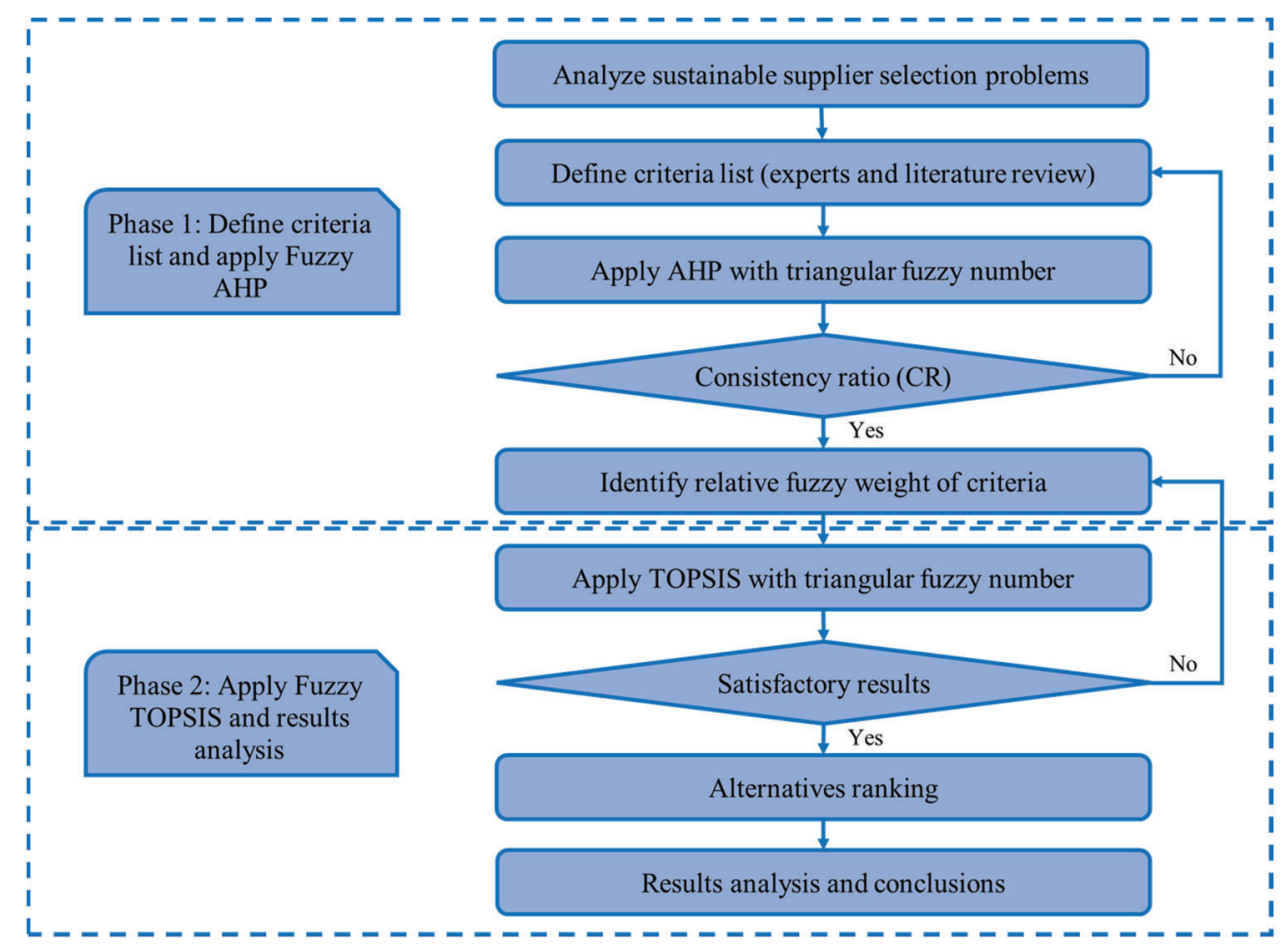

Figure 1: The process of paper

\subsection{Fuzzy Analytical Hierarchy Process (FAHP)}

Fuzzy sets, fuzzy numbers, and linguistic variables are reviewed by Buckley to handle uncertainties in decision-making problems [33]. Triangular fuzzy number (TFN) is a useful application in fuzzy theory, as illustrated in Tab. 3. According to assigned linguistic variables, the relative importance of two criteria is quantified on a number scale of $\tilde{1}-\tilde{9}$. To indicate imprecise data, a tilde symbol $(\sim)$ is inserted above the parameter symbols. Following that, the FAHP procedure is outlined as follows [34]:

Table 3: The fuzzy scale and its definition used in FAHP

\begin{tabular}{lll}
\hline Fuzzy set & Significant level & Triangular fuzzy scale \\
\hline$\tilde{1}$ & Equal & $(1,1,1)$ \\
$\tilde{2}$ & Light & $(1,2,3)$ \\
$\tilde{3}$ & Weak & $(2,3,4)$ \\
$\tilde{4}$ & Preferable & $(3,4,5)$ \\
$\tilde{5}$ & Importance & $(4,5,6)$ \\
$\tilde{6}$ & Fairly & $(5,6,7)$ \\
$\tilde{7}$ & Highly & $(6,7,8)$ \\
$\tilde{8}$ & Strongly & $(7,8,9)$ \\
$\tilde{9}$ & Extremely & $(8,9,10)$ \\
\hline
\end{tabular}


Step 1: The geometrical integration is utilized in the FAHP methods to provide an integrated fuzzy pairwise comparison matrix, $\widetilde{l_{i j}}$ represents the importance of the $i^{\text {th }}$ criterion over the $j^{\text {th }}$ criterion, as shown in Eq. (1):

$\widetilde{M}=\left(\begin{array}{cccc}1 & \widetilde{l_{12}} & \cdots & \widetilde{l_{1 n}} \\ \widetilde{l_{21}} & 1 & \cdots & \widetilde{l_{2 n}} \\ \cdots & \cdots & \cdots & \cdots \\ \widetilde{l_{n 1}} & \widetilde{l_{n 2}} & \cdots & 1\end{array}\right)=\left(\begin{array}{cccc}1 & \widetilde{l_{12}} & \cdots & \widetilde{l_{1 n}} \\ 1 / \widetilde{l_{12}} & 1 & \cdots & \widetilde{l_{2 n}} \\ \cdots \widetilde{\sigma} & \cdots & \cdots & \cdots \\ 1 / \widetilde{l_{1 n}} & 1 / \widetilde{l_{2 n}} & \cdots & 1\end{array}\right)$

where $\widetilde{l}_{i j}=\left\{\begin{array}{l}\widetilde{9}^{-1}, \widetilde{8}^{-1}, \widetilde{7}^{-1}, \widetilde{6}^{-1}, \widetilde{5}^{-1}, \widetilde{4}^{-1}, \widetilde{3}^{-1}, \widetilde{2}^{-1}, \widetilde{1}^{-1}, \widetilde{1}, \widetilde{2}, \widetilde{3}, \widetilde{4}, \widetilde{5}, \widetilde{6}, \widetilde{7}, \widetilde{8}, \widetilde{9} \begin{array}{r}\text { such that } i \neq j \\ \text { such that } i=j\end{array}\end{array}\right.$

Step 2: Fuzzy geometric mean of each criterion is computed using Eq. (2):

$\widetilde{r_{i}}=\left(\prod_{j=1}^{n} \widetilde{l_{i j}}\right)^{1 / n}$ such that $i=1,2, \ldots, n$

where $\widetilde{r_{i}}$ is the fuzzy geometrical mean, and $\widetilde{l_{i j}}$ is fuzzy comparison value from a group of decision-makers with respect to the $i^{\text {th }}$ criterion over the $j^{\text {th }}$ criterion.

Step 3: The relative fuzzy weight of each criterion is computed using Eq. (3):

$\widetilde{w_{i}}=\widetilde{r_{i}} \otimes\left(\widetilde{r_{1}} \oplus \widetilde{r_{2}} \oplus \ldots \oplus \widetilde{r_{n}}\right)^{-1}$

where $\widetilde{w}_{i}$ is the fuzzy weights of the $i^{t h}$ criterion.

Step 4: Defuzzify the relative fuzzy weights to get a crisp output using the average weight criteria $G_{i}$, as shown in Eq. (4):

$G_{i}=\frac{l w_{i}+m w_{i}+u w_{i}}{3}$

where $\widetilde{w}_{i}$ is the fuzzy weights of the $i^{t h}$ criterion, which can be presented as $\widetilde{w}_{i}=\left(l w_{i}, m w_{i}, u w_{i}\right)$, such that $l w_{i}, m w_{i}, u w_{i}$ are the lower-bound, middle-bound, and upper-bound of $\widetilde{w}_{i}$, respectively.

Step 5: The normalized preference weight of each criterion $H_{i}$, is computed in Eq. (5):

$H_{i}=\frac{G_{i}}{\sum_{i=1}^{n} G_{i}}$

\subsection{Fuzzy Technique for Order of Preference by Similarity to Ideal Solution (FTOPSIS)}

The TOPSIS method is extended to FTOPSIS in order to determine the optimal solution by evaluating the distance between the fuzzy positive ideal solution (FPIS) and the fuzzy negative ideal solution (FNIS) [35], which is described as follows:

Step 1: Identify the significance of the criteria using linguistic numbers. In this paper, the triangular fuzzy weight is obtained using the FAHP model.

Step 2: Identify the rating of the alternatives with respect to criteria using the linguistic numbers in Tab. 4. 
Table 4: Linguistics terms for ranking the alternatives

\begin{tabular}{lll}
\hline Linguistic level & Symbol & Triangular fuzzy scale \\
\hline Very poor & VP & $(0,0,1)$ \\
Poor & P & $(0,1,3)$ \\
Medium poor & MP & $(1,3,5)$ \\
Fair & F & $(3,5,7)$ \\
Medium good & MG & $(5,7,9)$ \\
Good & G & $(7,9,10)$ \\
Very good & VG & $(9,10,10)$ \\
\hline
\end{tabular}

Step 3: Build the fuzzy decision matrix and fuzzy weight using triangular fuzzy numbers using Eqs. (6) and (7):

$\tilde{D}=\left[\begin{array}{cccc}\tilde{x}_{11} & \tilde{x}_{11} & \cdots & \tilde{x}_{11} \\ \tilde{x}_{21} & \tilde{x}_{22} & \cdots & \tilde{x}_{2 n} \\ \vdots & \vdots & \vdots & \vdots \\ \tilde{x}_{m 1} & \tilde{x}_{m 2} & \cdots & \tilde{x}_{m n}\end{array}\right], \tilde{x}_{i j}=\frac{1}{k}\left(\tilde{x}_{i j}^{1} \oplus \tilde{x}_{i j}^{2} \oplus \ldots \oplus \tilde{x}_{i j}^{k}\right)$

$\tilde{W}=\left[\tilde{w}_{1}, \tilde{w}_{2}, \ldots, \tilde{w}_{n}\right]$

where $\tilde{x}_{i j}^{k}$ is the fuzzy rating of alternative $A_{i}$ with respect to criteria $C_{j}$ by $k^{\text {th }}$ decision-makers, $\tilde{x}_{i j}^{k}=\left(a_{i j}^{k}, b_{i j}^{k}, c_{i j}^{k}\right), i=1,2, \ldots, m, j=1,2, \ldots, n$.

Step 4: Build the fuzzy normalized decision matrix using Eqs (8)-(10):

$\tilde{R}=\left[\tilde{r}_{i j}\right]_{m \times n}, i=1,2, \ldots, m, j=1,2, \ldots, n$

$\tilde{r}_{i j}=\left(\frac{a_{i j}}{c_{j}^{+}}, \frac{b_{i j}}{c_{j}^{+}}, \frac{c_{i j}}{c_{j}^{+}}\right), c_{j}^{+}=\max _{i}\left\{c_{i j} \mid i=1,2, \ldots, m\right\}, j \in$ set of benefit

$\tilde{r}_{i j}=\left(\frac{a_{j}^{-}}{c_{i j}}, \frac{a_{j}^{-}}{b_{i j}}, \frac{a_{j}^{-}}{a_{i j}}\right), a_{j}^{-}=\min _{i}\left\{a_{i j} \mid i=1,2, \ldots, m\right\}, j \in$ set of cost

Step 5: Build the fuzzy weighted normalized decision matrix using Eq. (11):

$\tilde{V}=\left[\tilde{v}_{i j}\right]_{m \times n}, \tilde{v}_{i j}=\tilde{r}_{i j} \otimes \tilde{w}_{j}, i=1,2, \ldots, m, j=1,2, \ldots, n$

where $\tilde{w}_{j}$ denotes criteria fuzzy weight.

Step 6: Determine FPIS $A^{+}$(positive ideal) and FNIS $A^{-}$(negative ideal) using Eqs. (12) and (13):

$A^{+}=\left(\tilde{v}_{1}^{+}, \ldots, \tilde{v}_{j}^{+}, \ldots, \tilde{v}_{n}^{+}\right), \tilde{v}_{j}^{+}=(1,1,1), j=1,2, \ldots, n$

$A^{-}=\left(\tilde{v}_{1}^{-}, \ldots, \tilde{v}_{j}^{-}, \ldots, \tilde{v}_{n}^{-}\right), \tilde{v}_{j}^{-}=(0,0,0), j=1,2, \ldots, n$

Step 7: Calculate the distance $\left(d_{i}^{+}\right.$and $\left.d_{i}^{-}\right)$of each alternative from the positive and negative ideal solution using Eqs. (14) and (15): 
$\tilde{d}_{i}^{+}=\sum_{j=1}^{n} d\left(\tilde{v}_{i j}, \tilde{v}_{j}^{+}\right), i=1,2, \ldots, m$

$\tilde{d}_{i}^{-}=\sum_{j=1}^{n} d\left(\tilde{v}_{i j}, \tilde{v}_{j}^{-}\right), i=1,2, \ldots, m$

Step 8: Calculate the closeness coefficient of each alternative. The optimal solution is closer to the FPIS $A^{+}$and farther from the FNIS $A^{-}$, i.e., $\widetilde{C C}$ approaches to 1, using Eq. (16):

$\widetilde{C C}_{i}=\frac{\tilde{d}_{i}^{-}}{\tilde{d}_{i}^{+} \oplus \tilde{d}_{i}^{-}}, i=1,2, \ldots, m$

\section{Case Study}

The steel manufacturing industry is one of the key economic sectors in Vietnam. The steel sector in Vietnam continues to expand, and the domestic steel supply cannot meet the demand. Crude steel volume manufactured in Vietnam in 2018 amounted to 14.1 million tons, but local steel demand increased to 22.31 million tons. Therefore, it is estimated to take 3-5 years before the steel production can satisfy the market demand [36]. Many enterprises have invested in Vietnam's steel industry in recent years. Hence, supplier selection plays an important role in sustainable development. In this regard, a case study of the top 10 steel manufacturers in Vietnam is considered (Tab. 5). A set of criteria and definitions for green supplier selection are presented (Tab. 6). Five main aspects, including price (C1), quality (C2), delivery (C3), service (C4), and environment (C5), and 15 criteria are considered in this study, which are price criteria (product price, logistics cost, quantity discount), quality criteria (supply capacity, defect rate, reputation supplier), delivery criteria (lead time, on time delivery), service criteria (technology support, warranty, responsiveness, and flexibility), and environment criteria (air emissions, wastewater generation, energy consumption, green policies). After preliminary evaluation, a panel of experts who have many years of experience in the field of the steel industry in Vietnam are interviewed for rating the performance score on the criteria to all alternatives (Fig. 2). In this paper, the FAHP model was utilized for the determination of criteria fuzzy weights, then based on the most impactful criteria, then the FTOPSIS model was used to prioritize the most potential green supplier of steel manufacturing in Vietnam.

Table 5: List of suppliers used in this paper (unit: 1000 USD in 2020)

\begin{tabular}{|c|c|c|c|c|}
\hline No. & Supplier & Symbol & Operating expenses & Profit \\
\hline 1 & KKC Metal Joint-stock company (JSC) & $\mathrm{KKC}$ & 262 & 880 \\
\hline 2 & Vicasa Vnsteel Joint-stock company (JSC) & VCA & 1,435 & 3,783 \\
\hline 3 & Tung Kuang Industrial Joint-stock company (JSC) & TKU & 1,860 & 6,324 \\
\hline 4 & Dai Thien Loc Corporation & DTL & 1,097 & 8,529 \\
\hline 5 & Vietnam Germany Steel Pipe Joint-stock company (JSC) & VGS & 419 & 11,512 \\
\hline 6 & Pomina Steel Corporation & POM & 4,691 & 22,396 \\
\hline 7 & Nam Kim Steel Joint-stock company (JSC) & NKG & 4,058 & 38,377 \\
\hline 8 & Vietnam Steel Corporation & VSC & 30,756 & 76,691 \\
\hline 9 & Hoa Sen Group & HSG & 20,309 & 204,303 \\
\hline 10 & Hoa Phat Group Joint-stock company (JSC) & HPG & 30,478 & 834,653 \\
\hline
\end{tabular}


Table 6: A set of criteria and definitions

\begin{tabular}{|c|c|c|}
\hline Criteria & Attribute & Definition \\
\hline C11. Product price & Cost & The amount to be paid to purchase the products offered by the supplier \\
\hline C12. Logistics cost & Cost & Fixed shipping costs for product delivery \\
\hline C13. Quantity discount & Benefit & The supplier will give a percentage discount if quantity increases \\
\hline C21. Supply capacity & Benefit & The ability of a supplier to deliver a product within a predetermined period \\
\hline C22. Defect rate & Cost & The percentage of products that do not meet quality targets \\
\hline $\begin{array}{l}\text { C23. Reputation } \\
\text { supplier }\end{array}$ & Benefit & $\begin{array}{l}\text { The supplier information is clear, transparent in cooperation, and compliance } \\
\text { with the law }\end{array}$ \\
\hline C31. Lead time & Cost & The length of time from the beginning to the end of the production process \\
\hline C32. On time delivery & Benefit & Number of times the supplier delivered the product on a predetermined date \\
\hline $\begin{array}{l}\text { C41. Technology } \\
\text { support }\end{array}$ & Benefit & Technology capabilities, information security, and tracing ability \\
\hline C42. Warranty & Benefit & The period for which the supplier provides a warranty for the delivered product \\
\hline $\begin{array}{l}\text { C43. Responsiveness } \\
\text { and flexibility }\end{array}$ & Benefit & $\begin{array}{l}\text { The ability of the supply chain to respond intentionally to consumer demands } \\
\text { and within a reasonable period }\end{array}$ \\
\hline C51. Air emissions & Cost & Hazardous emission handling and quantity control \\
\hline $\begin{array}{l}\text { C52. Wastewater } \\
\text { generation }\end{array}$ & Cost & Wastewater treatment and quantity control \\
\hline $\begin{array}{l}\text { C53. Energy } \\
\text { consumption }\end{array}$ & Cost & $\begin{array}{l}\text { The energy used to carry out production activities of the enterprise such as } \\
\text { electricity, gas }\end{array}$ \\
\hline C54. Green policies & Benefit & $\begin{array}{l}\text { The commitment to sustainability and environmental management that business } \\
\text { makes such as green packaging, green production, green R\&D project }\end{array}$ \\
\hline
\end{tabular}

\section{Results Analysis}

\subsection{Results of the FAHP Model}

In the FAHP model, criteria are evaluated using linguistic words expressed as triangular fuzzy numbers with pessimistic value, most likely value, and optimistic value. The fuzzy geometrical mean is used to compute the relative weight of each criterion. Tab. 7 shows the relative importance of each criterion's fuzzy weight. As a consequence, the triangular fuzzy weight of criteria product price (C11), for example, has the lowest, middle, and highest values of $0.0320,0.0745$, and 0.1706 correspondingly. As the same concept, the triangular fuzzy weight of criteria logistics cost $(\mathrm{C} 12)$ has the lowest value of 0.0246 , the middle value of 0.0539 , and the highest value of 0.1230 . The remaining criteria have the same calculation.

The relative significant preference weight of criteria is depicted in Fig. 3. The result shows that lead time (C31), warranty (C42), defect rate (C22), supply capacity (C21), and product price (C11) have the most significant impact, at $8.802 \%, 8.625 \%, 8.235 \%, 7.968 \%$, and $7.643 \%$, respectively. The findings imply that decision-makers or policymakers in Vietnam should concentrate on those five key factors for enhancing the decision-making process of sustainable supplier evaluation and selection in the steel industry. 


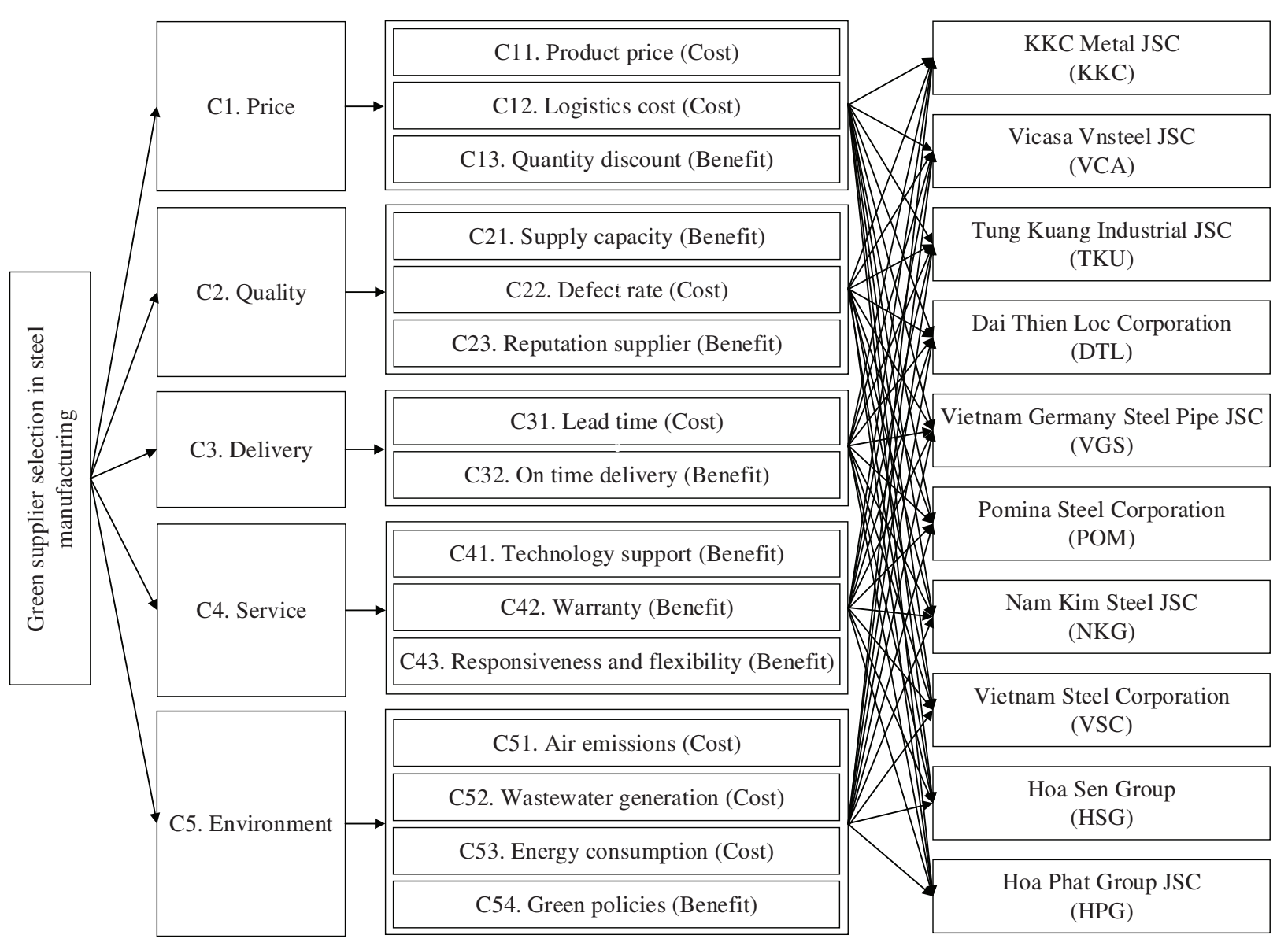

Figure 2: A hierarchy tree used in the FTOPSIS model

Table 7: The relatively important fuzzy weight of each criterion

\begin{tabular}{lcccccc}
\hline Criteria & \multicolumn{3}{c}{ Fuzzy geometric mean } & \multicolumn{3}{c}{ Fuzzy weights } \\
\hline C11. Product price & 0.7192 & 1.1422 & 1.7756 & 0.0320 & 0.0745 & 0.1706 \\
C12. Logistics cost & 0.5531 & 0.8264 & 1.2810 & 0.0246 & 0.0539 & 0.1230 \\
C13. Quantity discount & 0.5130 & 0.7441 & 1.1432 & 0.0228 & 0.0485 & 0.1098 \\
C21. Supply capacity & 0.7521 & 1.2159 & 1.8330 & 0.0334 & 0.0793 & 0.1761 \\
C22. Defect rate & 0.8503 & 1.2572 & 1.8604 & 0.0378 & 0.0820 & 0.1787 \\
C23. Reputation supplier & 0.7206 & 1.0272 & 1.5138 & 0.0320 & 0.0670 & 0.1454 \\
C31. Lead time & 0.9129 & 1.3616 & 1.9744 & 0.0406 & 0.0888 & 0.1897 \\
C32. On time delivery & 0.7216 & 1.0576 & 1.4967 & 0.0321 & 0.0689 & 0.1438 \\
C41. Technology support & 0.6543 & 0.9266 & 1.3270 & 0.0291 & 0.0604 & 0.1275 \\
C42. Warranty & 0.9577 & 1.3661 & 1.8839 & 0.0426 & 0.0891 & 0.1810 \\
C43. Responsiveness and flexibility & 0.5706 & 0.8360 & 1.2539 & 0.0254 & 0.0545 & 0.1204 \\
C51. Air emissions & 0.7899 & 1.1722 & 1.6705 & 0.0351 & 0.0764 & 0.1605 \\
C52. Wastewater generation & 0.6384 & 0.9215 & 1.3469 & 0.0284 & 0.0601 & 0.1294 \\
C53. Energy consumption & 0.5171 & 0.7252 & 1.0577 & 0.0230 & 0.0473 & 0.1016 \\
C54. Green policies & 0.5397 & 0.7595 & 1.0839 & 0.0240 & 0.0495 & 0.1041 \\
\hline
\end{tabular}




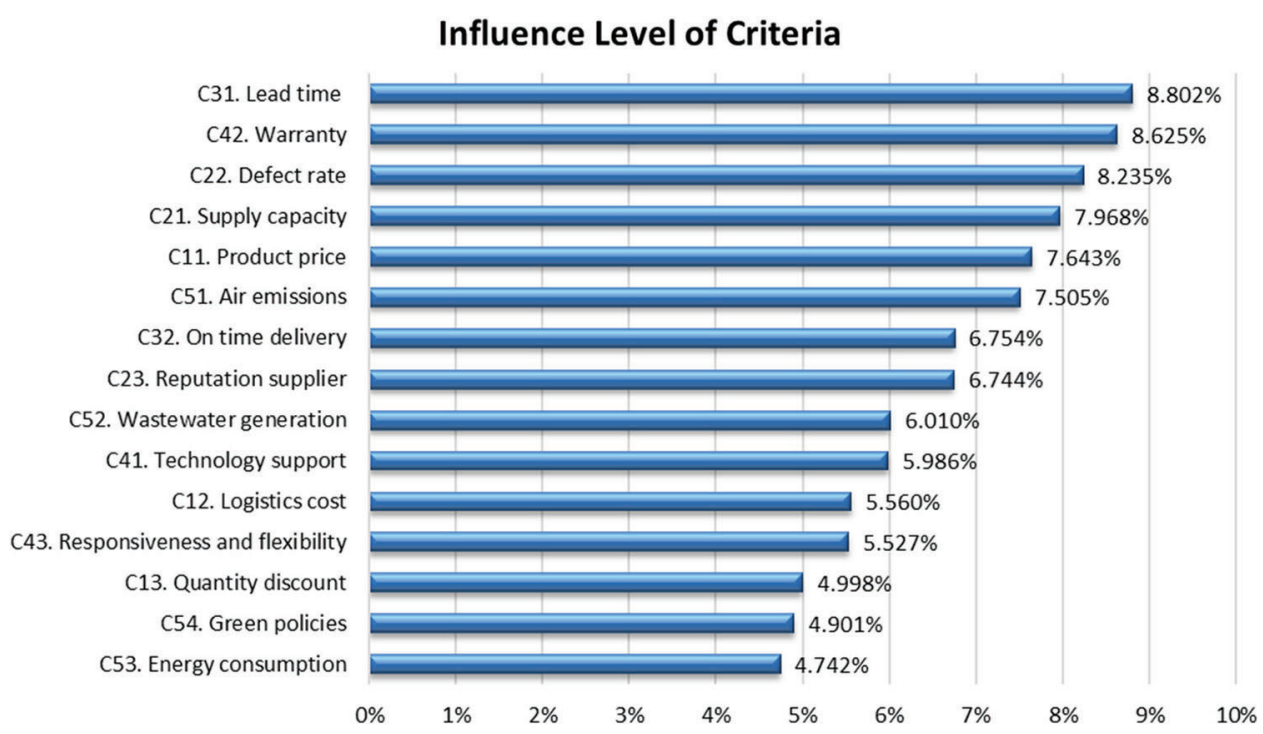

Figure 3: The influence level of criteria

\subsection{Results of the FTOPSIS Model}

The integrated fuzzy decision matrix, fuzzy normalized decision matrix, and fuzzy weighted normalized decision matrix are generated using the FTOPSIS method. The results of the FTOPSIS model are presented in Tab. 8 and Fig. 4. Based on the results, Hoa Phat Group Joint-stock company (HPG), Hoa Sen Group (HSG), and Pomina Steel Corporation (POM) are the top three prospective green suppliers, with ratings of $0.2464,0.1770$, and 0.0572 , respectively.

Table 8: Positive ideal, negative ideal, and gaps-degree calculation

\begin{tabular}{llllll}
\hline No. & Supplier & $d_{i}^{+}$ & $d_{i}^{-}$ & $C C_{i}$ & Rank \\
\hline 1 & KKC & 14.6593 & 0.4162 & 0.0276 & 6 \\
2 & VCA & 14.5835 & 0.5619 & 0.0371 & 8 \\
3 & TKU & 14.6664 & 0.3999 & 0.0265 & 4 \\
4 & DTL & 14.4945 & 0.5983 & 0.0396 & 10 \\
$\mathbf{5}$ & VGS & $\mathbf{1 4 . 7 2 2 0}$ & $\mathbf{0 . 3 4 3 6}$ & $\mathbf{0 . 0 2 2 8}$ & $\mathbf{3}$ \\
6 & POM & 14.3974 & 0.8734 & 0.0572 & 7 \\
7 & NKG & 14.6809 & 0.4613 & 0.0305 & 5 \\
8 & VSC & 14.4885 & 0.7444 & 0.0489 & 9 \\
$\mathbf{9}$ & HSG & $\mathbf{1 4 . 7 7 5 1}$ & $\mathbf{3 . 1 7 7 5}$ & $\mathbf{0 . 1 7 7 0}$ & $\mathbf{1}$ \\
$\mathbf{1 0}$ & HPG & $\mathbf{1 4 . 8 2 7 7}$ & $\mathbf{4 . 8 4 7 4}$ & $\mathbf{0 . 2 4 6 4}$ & $\mathbf{2}$ \\
\hline
\end{tabular}




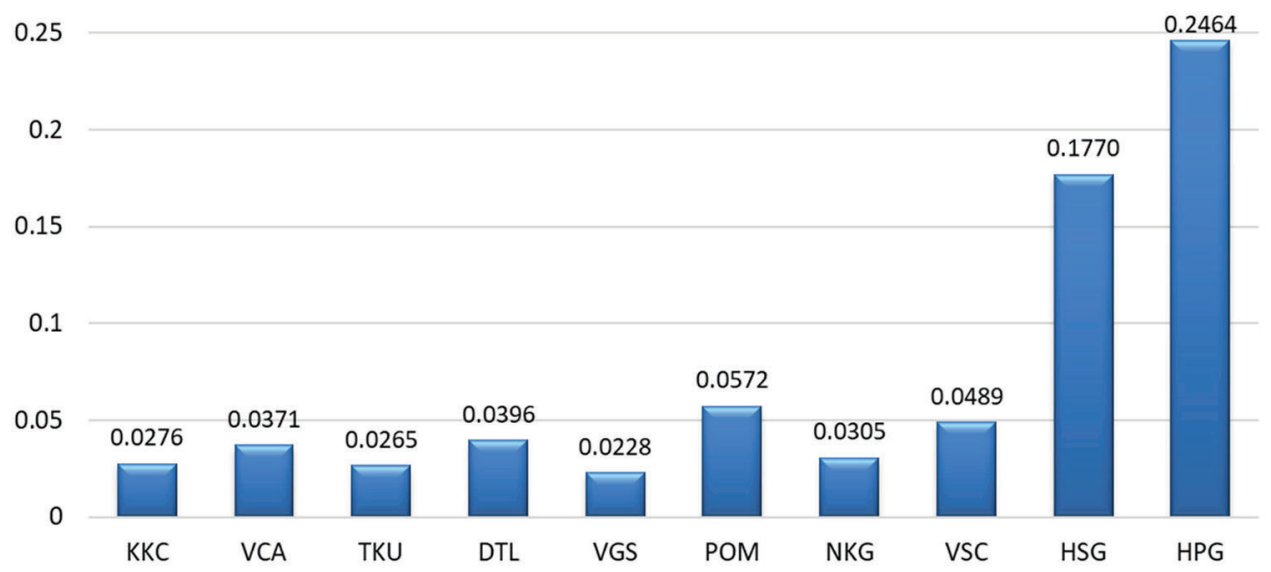

Figure 4: Ranking of suppliers

\section{Conclusions and Future Studies}

The study is practical and vital since steel is one of the most important products in many countries. Vietnam is one of the developing countries in Asia that needs the steel industry to build its railroads, bridges, buildings, and many more. Green suppliers in the steel industry are a good consideration since many countries are shifting to green energy. The criteria also specify the factors that a steel manufacturer must consider. With growing international concerns about natural resource depletion, environmental pollution, and global warming, green supplier selection is currently receiving a lot of attention. Also, green supplier selection contributes to enhanced productivity and customer satisfaction by offering consumers options to reduce their environmental impact, preserve resources, and save prices [37]. The application of green technologies helps the steel manufacturing industry incorporate environmental concerns into their strategic objectives to adapt to environmental requirements and gain a competitive edge over national and international rivals. With a developing country like Vietnam today, the issue of environmental protection is even more concerned. Furthermore, this issue is still underexplored in the context of emerging countries. To the best of our knowledge, the present work is the first research of its type aimed at identifying the best green supplier for the steel manufacturing industry in Viet Nam through a picture of fuzzy MCDM by combining FAHP and FTOPSIS models.

The steel manufacturing business has a significant turnover in its supply chain. With this, supplier selection plays a critical role in gaining competitive advantages. This study employs a two-stage fuzzy MCDM method by considering 15 criteria to prioritize the top 10 steel suppliers in Vietnam. Besides four conventional criteria (price, quality, delivery, and services), the environment factor is also included. By using fuzzy set theory, experts' preferences are transformed into accurate outcomes by using qualitative linguistic terms. The FAHP model was used to investigate the impact of criterion weights on supplier selection. Then, the FTOPSIS model was used for ranking suppliers. Although there is no substantial difference between Hoa Sen Group (HSG) and Hoa Phat Group Joint-stock company (HPG), the findings suggest that HPG is the most suitable supplier. The company can choose to work with all of these suppliers, but HPG has the first priority. The most important contributions and achievements of this study can be summarized as follows:

- The study selected and evaluated the most influential factors in the steel manufacturing sector in Vietnam by interviewing experts and studying the literature, which is a key benefit of this research. 
- A case study of evaluating suppliers for the Vietnamese steel manufacturing industry utilizing the suggested framework (i.e., FAHP and FTOPSIS) was conducted to demonstrate the model's effectiveness.

- The criteria of "lead time", "warranty", "defect rate", "supply capacity", and "product price" were determined as the most influential criteria in the FAHP model.

- From the final ranking of FTOPSIS, "Hoa Phat Group Joint-stock company", "Hoa Sen Group", and "Pomina Steel Corporation" are the top three potential green suppliers for steel manufacturing in Vietnam.

- The managerial implications of this paper can be a useful guideline in the supplier evaluation and selection sector not only for steel manufacturing managers but also for the decision-makers and investors in other industries.

For future studies involving quantitative and qualitative approaches, the authors suggest investigating new assessment criteria that can impact the green supplier selection process in order to improve the solution of the case study. In this paper, the method's efficacy is based on expert validation. It is also recommended that the sensitivity analysis and comparative analysis should be integrated into future studies to demonstrate the applicability and robustness of the proposed model. This paper used triangular fuzzy numbers to handle the uncertainty in the decision-making process. Further extension can be performed by incorporating uncertainty in the form of fuzzy, hesitant fuzzy, intuitionistic fuzzy, neutrosophic fuzzy, or probabilistic information. A comparison with this work may provide more insight.

Furthermore, the proposed method might be useful for a variety of MCDM problems, such as management challenges (i.e., location selection and project management) and marketing challenges (i.e., new products creation and promotion activities) when available data are imprecise and uncertain by nature. Other MCDM methods (i.e., FANP, VIKOR, WASPAS) can also be considered to develop a fuzzy group decision support system for supplier selection management decision problems in future studies [38,39].

Acknowledgement: The authors appreciate the support from the National Kaohsiung University of Science and Technology, Taiwan.

Funding Statement: The authors received no specific funding for this study.

Conflicts of Interest: The authors declare that they have no conflicts of interest to report regarding the present study.

\section{References}

[1] C. Wu and D. Barnes, "A literature review of decision-making models and approaches for partner selection in agile supply chains," Journal of Purchasing and Supply Management, vol. 17, no. 1, pp. 256-274, 2011.

[2] N. Ben Mabrouk, A. Ben Mabrouk and B. Jarraya, "Factors influencing the performance of supply chain management in Saudi SMEs," Uncertain Supply Chain Management, vol. 8, no. 3, pp. 569-578, 2020.

[3] R. Villanueva-Ponce, L. Avelar-Sosa, A. Alvarado-Iniesta and V. G. Cruz-Sánchez, "The green supplier selection as a key element in a supply chain: A review of cases studies," Dyna, vol. 82, no. 194, pp. 36-45, 2015.

[4] N. Ben Mabrouk, "Interpretive structural modeling of critical factors for buyer-supplier partnerships in supply chain management," Uncertain Supply Chain Management, vol. 8, no. 3, pp. 613-626, 2020.

[5] P. Sasikumar and K. E. K. Vimal, "Evaluation and selection of green suppliers using fuzzy VIKOR and fuzzy TOPSIS," in Emerging Applications in Supply Chains for Sustainable Business Development, vol. 12, pp. 202-218, 2019.

[6] F. Vimal, "An interactive solution approach for multiple objective supplier selection problem with fuzzy parameters," Journal of Intelligent Manufacturing, vol. 26, no. 5, pp. 989-998, 2015. 
[7] A. J. Deshmukh and H. Vasudevan, "Emerging supplier selection criterion in the context of traditional vs. green supply chain management," International Journal of Managing Value and Supply Chains, vol. 5, no. 1, pp. 19, 2014.

[8] N. Banaeian, H. Mobli, B. Fahimnia, I. E. Nielsen and M. Omid, "Green supplier selection using fuzzy group decision making methods: A case study from the agri-food industry," Computers \& Operations Research, vol. 89, pp. 337-347, 2018.

[9] P. Jiang, Y. C. Hu, G. F. Yen and S. J. Tsao, "Green supplier selection for sustainable development of the automotive industry using grey decision-making," Sustainable Development, vol. 26, no. 6, pp. 890-903, 2018.

[10] Z. Lu, X. Sun, Y. Wang and C. Xu, "Green supplier selection in straw biomass industry based on cloud model and possibility degree," Journal of Cleaner Production, vol. 209, pp. 995-1005, 2018.

[11] A. Arabsheybani, M. M. Paydar and A. S. Safaei, "An integrated fuzzy MOORA method and FMEA technique for sustainable supplier selection considering quantity discounts and supplier's risk," Journal of Cleaner Production, vol. 190, pp. 577-591, 2018.

[12] M. Almasi, S. Khoshfetrat and M. Rahiminezhad Galankashi, "Sustainable supplier selection and order allocation under risk and inflation condition," IEEE Transactions on Engineering Management, vol. 68, no. 3, pp. 823-837, 2019.

[13] J. Li, H. Fang and W. Song, "Sustainable supplier selection based on SSCM practices: A rough cloud TOPSIS approach," Journal of Cleaner Production, vol. 222, pp. 606-621, 2019.

[14] S. Gupta, U. Soni and G. Kumar, "Green supplier selection using multi-criterion decision making under fuzzy environment: A case study in automotive industry," Computers \& Industrial Engineering, vol. 136, pp. 663680, 2019.

[15] H. S. Kilic and A. S. Yalcin, "Modified two-phase fuzzy goal programming integrated with IF-TOPSIS for green supplier selection, Applied Soft Computing, vol. 93, pp. 106371, 2020.

[16] K. R. Ramakrishnan and S. Chakraborty, "A cloud TOPSIS model for green supplier selection," Facta Universitatis," Series: Mechanical Engineering, vol. 18, no. 3, pp. 375-397, 2020.

[17] A. Çalık, "A novel Pythagorean fuzzy AHP and fuzzy TOPSIS methodology for green supplier selection in the industry 4.0 era," Soft Computing, vo, vol. 25, no. 3, pp. 2253-2265, 2021.

[18] D. Kannan, K. Govindan and S. Rajendran, "Fuzzy axiomatic design approach based green supplier selection: A case study from Singapore," Journal of Cleaner Production, vol. 96, pp. 194-208, 2015.

[19] F. Dweiri, S. Kumar, S. A. Khan and V. Jain, "Designing an integrated AHP based decision support system for supplier selection in automotive industry," Expert Systems with Applications, vol. 62, pp. 273-283, 2016.

[20] G. Büyüközkan and F. Göçer, "Application of a new combined intuitionistic fuzzy MCDM approach based on axiomatic design methodology for the supplier selection problem," Applied Soft Computing, vol. 52, pp. 1222-1238, 2017.

[21] S. Luthra, K. Govindan, D. Kannan, S. K. Mangla and C. P. Garg, "An integrated framework for sustainable supplier selection and evaluation in supply chains," Journal of Cleaner Production, vol. 140, pp. 1686-1698, 2017.

[22] A. Awasthi, K. Govindan and S. Gold, "Multi-tier sustainable global supplier selection using a fuzzy AHPVIKOR based approach," International Journal of Production Economics, vol. 195, pp. 106-117, 2018.

[23] A. Azimifard, S. H. Moosavirad and S. Ariafar, "Selecting sustainable supplier countries for Iran's steel industry at three levels by using AHP and TOPSIS methods," Resources Policy, vol. 57, pp. 30-44, 2018.

[24] H. W. Lo, J. J. Liou, H. S. Wang and Y. S. Tsai, "An integrated model for solving problems in green supplier selection and order allocation," Journal of Cleaner Production, vol. 190, pp. 339-352, 2018.

[25] E. Durmić, "Evaluation of criteria for sustainable supplier selection using FUCOM method," Operational Research in Engineering Sciences: Theory and Applications, vol. 2, no. 1, pp. 91-107, 2019.

[26] G. Pishchulov, A. Trautrims, T. Chesney, S. Gold and L. Schwab, "The voting analytic hierarchy process revisited: A revised method with application to sustainable supplier selection," International Journal of Production Economics, vol. 211, pp. 166-179, 2019.

[27] K. Rashidi and K. Cullinane, "A comparison of fuzzy DEA and fuzzy TOPSIS in sustainable supplier selection: Implications for sourcing strategy," Expert Systems with Applications, vol. 121, pp. 266-281, 2019. 
[28] S. A. Roy, S. M. Ali, G. Kabir, R. Enayet, S. A. Suhi et al., "A framework for sustainable supplier selection with transportation criteria," International Journal of Sustainable Engineering, vol. 13, no. 2, pp. 77-92, 2020.

[29] H. Taherdoost and A. Brard, "Analyzing the process of supplier selection criteria and methods," Procedia Manufacturing, vol. 32, pp. 1024-1034, 2019.

[30] F. Ecer and D. Pamucar, "Sustainable supplier selection: A novel integrated fuzzy best worst method (F-BWM) and fuzzy CoCoSo with Bonferroni (CoCoSo'B) multi-criteria model," Journal of Cleaner Production, vol. 266, pp. 121981, 2020.

[31] E. B. Tirkolaee, A. Mardani, Z. Dashtian, M. Soltani and G. W. Weber, "A novel hybrid method using fuzzy decision making and multi-objective programming for sustainable-reliable supplier selection in two-echelon supply chain design,” Journal of Cleaner Production, vol. 250, pp. 119517, 2020.

[32] C. N. Wang, N. A. T. Nguyen, T. T. Dang and C. M. Lu, "A compromised decision-making approach to third-party logistics selection in sustainable supply chain using fuzzy AHP and fuzzy VIKOR methods," Mathematics, vol. 9, no. 8, pp. 886, 2021.

[33] J. J. Buckley, "Fuzzy hierarchical analysis," Fuzzy Sets and Systems, vol. 17, pp. 233-247, 1985.

[34] N. B. T. Nguyen, G. H. Lin and T. T. Dang, "A two phase integrated fuzzy decision-making framework for green supplier selection in the coffee bean supply chain," Mathematics, vol. 9, no. 16, pp. 1923, 2021.

[35] C. N. Wang, T. T. Dang and N. A. T. Nguyen, "Outsourcing reverse logistics for e-commerce retailers: A twostage fuzzy optimization approach," Axioms, vol. 10, no. 1, pp. 34, 2021.

[36] Vietnam's Steel Market to 2024, 2020. [Online]. Available: https://www.prnewswire.com/news-releases/ vietnams-steel-market-to-2024-production-volume-of-crude-steel-is-projected-to-exceed-20-cagr-during-20202024-300992785.html.

[37] H. Gupta and M. K. Barua, "Supplier selection among SMEs on the basis of their green innovation ability using BWM and fuzzy TOPSIS," Journal of Cleaner Production, vol. 152, pp. 242-258, 2017.

[38] N. B. T. Nguyen, G. H. Lin and T. T. Dang, "Fuzzy multi-criteria decision-making approach for online food delivery (OFD) companies evaluation and selection: A case study in Vietnam," Processes, vol. 9, no. 8, pp. 1274, 2021.

[39] Q. Wu, L. Zhou, Y. Chen and H. Chen, "An integrated approach to green supplier selection based on the interval type-2 fuzzy best-worst and extended VIKOR method," Information Sciences, vol. 502, pp. 394-417, 2019. 